\section{Uma breve síntese do livro pioneiro sobre a transição para a vida adulta no Brasil}

\author{
Aída C.G. Verdugo Lazo*
}

\begin{abstract}
CAMARANO, A.A. Transição para a vida adulta ou vida adulta em transição? Rio de Janeiro: Ipea, 2006 (332 páginas).
\end{abstract}

O tema deste livro é de grande interesse para os cientistas sociais brasileiros que desejam conhecer os processos que levam os indivíduos a saírem da dependência infantil e adquirirem responsabilidades e autonomias próprias de um cidadão adulto. A definição clássica de Modell, Furstenberg Jr. e Hershberg (1976) estabelece que essa transição é um processo marcado por eventos específicos, como a saída da escola, a entrada na força de trabalho, a saída da família de origem, o casamento e o estabelecimento de uma nova família. A linearidade dessa proposta passou a ser colocada à prova em distintas sociedades, assim como no Brasil, com as mudanças ocorridas no mundo do trabalho, nos arranjos familiares e na nupcialidade, como mencionam Camarano e Mello no capítulo introdutório deste livro.

Questões relativas aos jovens, tais como instabilidade e precariedade de inserção no mercado de trabalho, gravidez na adolescência e violência nas grandes cidades, são temas que estão na agenda tanto das políticas públicas como dos estudiosos da população. Dados apresentados por Camarano e Mello são definitivos: no Brasil, em $2000,28 \%$ da população brasileira estava na faixa de 15 a 29 anos e aí se encontravam $58 \%$ de todos os desempregados do país; do total de óbitos causados por homicídios, 57\% ocorreram nesse segmento etário; das jovens de 15 a 19 anos, $15 \%$ já tinham tido filhos e quase metade dessas mães morava na casa dos pais ou parentes.

Com estas evidências, Ana Amélia Camarano organiza o livro Transição para a vida adulta ou vida adulta em transição? segundo três grandes temas: o primeiro (Parte 1) reúne três capítulos sobre as transições ao longo do ciclo da vida; o segundo (Parte 2) engloba quatro capítulos sobre os processos que levam à transição; e o último (Parte 3) trata, em dois capítulos, das transições negadas ou não-transições. O livro conta ainda com um capítulo introdutório (capítulo 1) e um de considerações finais (capítulo 11).

Na primeira parte, são descritos, no capítulo 2, os principais estados, cujas transições marcariam as fases do ciclo de vida da população, considerando-se cinco fatores: freqüência à escola; atividade econômica; constituição de domicílio; casamento; morte; e maternidade no caso das mulheres. As autoras concluem que, a despeito das mudanças recentes em todo o ciclo de vida, de maneira geral, as principais fases da vida, sua seqüência e seus eventos continuam os mesmos citados nos textos clássicos. Juntamente com o prolongamento da vida, observam-se outros prolongamentos, como o tempo passado na escola e no período pós-laboral. Além disso, verificou-se que as principais mudanças foram experimentadas pelas mulheres.

Seguindo a linha de análise anterior, no capítulo 3, as autoras estudam, na primeira parte, as transições ao longo da vida para homens e mulheres nas Regiões Nordeste e Sudeste. Na segunda parte, é abordada a análise por cor. Suas conclusões apontam para um ciclo de vida dividido em três fases: infância e adolescência ou primeira idade; vida adulta ou segunda idade; e velhice ou terceira idade, para todos os subgrupos populacionais considerados. Essas fases estariam claramente delimitadas, para os homens, pelos eventos relacionados ao mercado de trabalho e, para as mulheres, pelo casamento e mater-

"Pesquisadora titular, Ence/IBGE. 
nidade. As principais diferenças encontradas foram entre homens e mulheres residentes no Nordeste e no Sudeste e entre brancos e negros.

O capítulo 4 é o mais importante da Parte 1 do livro, em que as autoras analisam a transição para a vida adulta (ou vida adulta em transição?), procurando verificar como este processo variou no Brasil entre 1980 e 2000. Partindo dessa perspectiva, são considerados os cinco eventos clássicos da transição para a vida adulta: a saída da escola; a entrada no mercado de trabalho; o casamento; a saída da casa dos pais; e a maternidade (para as mulheres). A população estudada compreende duas coortes: pessoas que nasceram entre 1950 e 1965 (coorte 1) e tinham entre 15 e 29 anos, no censo de 1980, e 35 a 49 anos, no censo de 2000; e aquelas que nasceram entre 1970 e 1985 (coorte 2) e estavam na faixa etária de 15 a 29 anos, no censo de 2000.

Sempre com base numa estimação indireta dos eventos de transição, uma das maiores mudanças observadas pelas autoras refere-se ao início desse processo de transição: enquanto em 1980, aos 15 anos, $50 \%$ já tinham deixado a escola, essa proporção reduziu-se para $10 \%$ em 2000 . Conseqüência desse adiamento foi o crescimento da participação simultânea na escola e no trabalho. Isso leva as autoras a se perguntarem: qual dos dois eventos define o início do processo de transição para a vida adulta nesse caso? Por outro lado, com o aumento da escolaridade das mulheres, que as levou ao crescimento de sua participação no mercado de trabalho, abriram-se novas alternativas de transição. Dessa forma, o processo de transição ficou mais complexo e heterogêneo; mesmo assim, os jovens continuam transitando para a vida adulta, majoritariamente, nos moldes tradicionais.

A segunda parte do livro tem como destaque a incorporação de alguns capítulos escritos por especialistas que não se detêm apenas na descrição do fenômeno em estudo, incorporando sua experiência e outras fontes de dados, além dos censos, para discutir questões como a educação e sua desigualdade no tempo da juventude (capítulo 5, de Felícia Madeira), os jovens e o trabalho em mercados sob intensas transições ocupacionais (capítulo 6, de Nadya Guimarães) e parentalidade juvenil (capítulo 8, de Maria Luiza Heilborn e Cristiane Cabral).

Na sua discussão, Felícia Madeira ilustra de forma mais detalhada a importância do ensino médio e seus reflexos na redução da maternidade precoce, entre as jovens, e dos homicídios, entre os jovens do sexo masculino, considerando informações do Estado de São Paulo. Quanto às perspectivas das crianças nascidas em $2000 \mathrm{em}$ relação àquelas nascidas em 1980, a autora lembra exercício de Rios-Neto (2005), que afirma que a coorte de 2000 terá muito mais chances de atingir o ensino médio e com proporção superior de concluintes do que a de 1980, tratando-se de uma segunda transição demográfica, marcada pelo prolongamento do espaço da juventude e aumento do ritmo de mobilidade.

Para Nadya Guimarães, o debate sobre a transição para a vida adulta tem uma das suas âncoras mais importantes no âmbito do trabalho, pois a inserção no mercado de trabalho constitui não somente um dos momentos privilegiados da transição, mas também a condição necessária para que outras dimensões da passagem da adolescência para a vida adulta se efetivem. Baseada em um survey atitudinal de jovens, de âmbito nacional, realizado em 2003, a autora relata que, para os jovens brasileiros, o trabalho destacava-se entre os assuntos atuais de maior importância, assim como entre os problemas que mais os preocupavam. A autora também considera as trajetórias de jovens em busca de emprego, abordando dados de 1997 a 2001 de pesquisa conduzida na Região Metropolitana de São Paulo. Entre os jovens, predomina um tipo de trajetória errática que poder-seia considerar "tentativa", com entradas e saídas e circulando com freqüência entre o desemprego e a inatividade. Entretanto, a autora também destaca um grupo, quase tão importante quanto o anterior, duradouramente integrado ao mercado em posição estável, como assalariados com carteira ou funcionários públicos. Por último, 
outros vivem sob intensa circulação entre situações que não permitem identificar um tipo dominante de trajetória e em que a insegurança é a norma.

Maria Luiza Heilborn e Cristiane Cabral abordam a temática da juventude segundo a perspectiva da sexualidade e da reprodução, discutindo em que medida os eventos biográficos da maternidade e paternidade podem ser compreendidos como formas de transição para a vida adulta. Uma discussão abrangente e completa é feita com as informações provenientes da pesquisa "Gravidez na adolescência: estudo multicêntrico sobre jovens, sexualidade e reprodução no Brasil", realizada entre 1999 e 2002. As autoras verificam que é marcante o contraste em termos de nível escolar atingido entre os jovens com e sem filhos. Os primeiros têm majoritariamente baixa escolaridade: quase metade possui somente o nível fundamental incompleto. Porém, a gravidez e o nascimento da criança ocorrem em grande proporção após a interrupção e/ou conclusão dos estudos. Entretanto, as autoras verificam que o evento da paternidade/maternidade é posterior à aquisição do primeiro emprego/atividade remunerada, sobretudo entre os homens, o que fortalece sua hipótese de que a reprodução pode ser, para muitos jovens, a conclusão da transição para a vida adulta. Outra evidência neste sentido refere-se ao fato de que pouco mais da metade dos jovens pais e mães não mora com os próprios pais ou adultos responsáveis e cerca de $60 \%$ se declararam casados ou coabitando com parceiro.

Nesta segunda parte, Camarano, Mello, Kanso e Andrade também discutem o processo de constituição da família entre os jovens (capítulo 7). A análise parte do pressuposto de que a posição de um indivíduo no domicílio pode indicar seu status e, no caso específico dos jovens, sugerir o estágio em que se encontram no processo de passagem para a vida adulta. Operacionalmente, as autoras definiram duas categorias de domicílios onde residem jovens: domicílios de jovens, onde o jovem estava na condição de chefe ou cônjuge; e domicílios com jovens, nos quais ele ocupa qualquer outra condição. Em uma primeira aproximação, utilizando os dados dos censos de 1980 e 2000, observou-se redução na proporção de domicílios de jovens, sinalizando um adiamento na saída de casa no período. Entretanto, verificouse que, mesmo tendo aumentado os domicílios com jovens, entre 1980 e 2000, $7,1 \%$ dos jovens que moravam neste tipo de domicílio eram casados, 5,7\% separados e, entre as mulheres, $10,9 \%$ já tinham tido filhos. Assim, o fato de os jovens morarem na casa dos pais não significa que não tenham constituído família, saído da casa dos pais e depois retornado ou nunca terem saído. Isto coloca em evidência, mais uma vez, a necessidade do levantamento de histórias de vida para tratar deste tema. Como as autoras colocam nas suas considerações finais, devido à indisponibilidade de dados, não foi possível concluir se o processo de saída de casa é ou não reversível no tempo, mas assume-se a sua possibilidade. Outro resultado interessante destacado diz respeito às famílias constituídas pelos jovens - tanto em domicílios de jovens como naqueles com jovens, que já apresentavam características de um estágio de formação mais avançado, ou seja, não eram compostas por pessoas sozinhas ou por casal sem filho, mas tinham pelo menos um filho. Este resultado sugere a importância da parentalidade no processo de constituição da família ou de conclusão da transição para a vida adulta, como apontado por Heilborn e Cabral, no capítulo 8.

A terceira parte do livro trata das "transições negadas ou não-transições". O tema é discutido em dois capítulos (9 e 10). No primeiro, Camarano, Kanso, Mello e Andrade consideram os jovens que não estudam, não trabalham e não procuram trabalho: são majoritariamente mulheres, com idade média ao redor de 22,5 anos, brancas e com menor nível de escolaridade. Com relação à posição no domicílio onde residem, a maioria é composta por filhos(as), solteiros(as) e a renda per capita é a mais baixa. Além de descrever as características desses jovens, neste capítulo, as autoras buscam medir o impacto de algumas variáveis na 
chance de um jovem se encontrar na categoria estudada. Utilizando um modelo de regressão logística, entre as covariáveis consideradas, a que mostrou maior impacto na probabilidade de pertencer ao grupo que não estuda, nem participa do mercado de trabalho, para ambos os sexos, é a de ser portador de algum tipo de paralisia física.

No capítulo 10, Helder Ferreira e Herton Araújo tratam das transições negadas, tendo como foco principal os jovens de 15 a 29 anos que morrem por homicídios. Se, no total de óbitos da população masculina em 2000, $8 \%$ ocorreram por causas externas, entre aqueles referentes aos jovens esse percentual chegou a $74 \%$. Os autores colocam que, com relação à intencionalidade, as causas externas podem ser divididas em dois casos: os acidentes, sem intencionalidade; e os homicídios e suicídios, cuja intenção é de ceifar a vida. Dessas causas de morte, o homicídio era a principal entre os jovens de 15 a 29 anos, com cerca de $60 \%$ em 2000. Os acidentes de transporte e outras causas externas (inclusive suicídio) vinham praticamente empatados em segundo lugar, cada um com cerca de $20 \%$ do total dessas causas. No caso dos homicídios, as mulheres dessa faixa etária morriam 15 vezes menos do que os homens, mas cabe ressaltar que, mesmo entre as mulheres, as maiores taxas de homicídios concentravam-se no grupo de 15 a 29 anos.

Observando as mortes por causas violentas em geral, os autores concluem que hoje vivemos em um país mais violento do que nos últimos 20 anos de século XX. Eles incluem ainda uma breve análise internacional, utilizando um banco de dados sobre homicídios da OMS e finalizam com uma discussão ampla sobre algumas causas de homicídio e da violência em geral, dialogando com um artigo de Briceño-León (2005), que procura construir uma estrutura de interpretação sociológica sobre a violência urbana na América Latina. Os autores consideram o que denominam de fatores macrossociais, mesossociais e microssociais, e encerram o capítulo com uma importante discussão sobre possíveis ações a serem empreendidas no sentido de contribuir para a redução dessa mortalidade violenta.

O grande desafio enfrentado pelos autores para o estudo da transição para a vida adulta no Brasil refere-se às restrições das informações disponíveis nos censos ou pesquisas amostrais, que não contam com histórias de vida, as quais permitiriam o estudo do tema de forma direta. As transições são constituídas por eventos claramente datados, como a saída da escola, o início do primeiro emprego, a saída da casa de origem, a data do primeiro casamento, a data de nascimento do primeiro filho. Essas informações não estão disponíveis, salvo de forma parcial na Pesquisa sobre Padrões de Vida realizada pelo IBGE, em 1996-1997, que também apresenta restrições amostrais, não oferecendo uma visão completa ao nível nacional. Diante disso, Camarano, Kanso, Mello e Andrade utilizam, ao longo dos capítulos de sua responsabilidade, uma metodologia indireta de coorte sintética, para poder aproveitar as informações disponíveis nos censos demográficos de 1980 e 2000 para o estudo proposto. O objetivo das autoras é obter estimações que ofereçam um indicativo das características e tendências observadas nesse período.

No tocante ao objetivo do livro, não é prioritário destacar a metodologia utilizada, mas, do ponto de vista acadêmico, teria sido de grande interesse incluir uma discussão ampla sobre este aspecto, detalhando mais especificamente a metodologia utilizada, assim como colocar em evidência a necessidade de pesquisas específicas para um tratamento mais rigoroso e profundo do tema.

Finalmente, pode-se afirmar que a maior contribuição deste livro é seu caráter inovador no estudo do tema da transição para a vida adulta no Brasil. O grande volume de informação que disponibiliza abre perspectivas e estimula a realização de outros estudos neste tema no futuro. 


\section{Referências bibliográficas}

BRICEÑO-LEÓN, R. The author replies. Cadernos de Saúde Pública, v.21, n.6, p.1.659-1.664, nov./dez. 2005.

MODELL, J.; FURSTENBERG Jr., F.; HERSHBERG, T. Social change and transitions to adulthood in historical perspective. Journal of Family History,
Minneapolis (USA), NCFR, v.38, n.1, p. 732, 1976.

RIOS-NETO, E.L.G. Questões emergentes na análise demográfica: o caso brasileiro. Revista Brasileira de Estudos de População, São Paulo, v.22, n.2, p. 371408, jul./dez. 2005.

Recebido para publicação em 22/02/2007. Aceito para publicação em 31/05/2007. 